\title{
John Locke e o direito de resistência
}

\author{
John Locke and the right of resistance
}

Flávio Gabriel Capinzaiki Ottonicar ${ }^{1}$

\begin{abstract}
1 Bacharel e Mestre em Filosofia pela Universidade Estadual Paulista, Brasil. E-mail: fottonicar@gmail.com
\end{abstract}

RESUMO: Na sua principal obra política, os Dois Tratados Sobre o Governo, Locke defende o direito do indivíduo de resistir ao soberano. Entretanto, segundo Locke, o ser humano abandona o estado de natureza voluntariamente para criar o Estado político com a esperança de que o poder político amenize as inconveniências do estado de natureza. Se a criação do Estado político foi voluntária, em que circunstâncias se deve resistir às determinações do soberano? Além disso, como fundamentar o direito de resistência ao soberano que foi instituído com a permissão do próprio indivíduo que agora pretende resistir as suas determinações? O objetivo do presente texto é discutir os motivos pelos quais a defesa do direito de resistência se torna necessária no pensamento político de Locke, e de que forma e com quais fundamentos Locke defende tal direito no Segundo Tratado Sobre o Governo. Pretende-se reconstruir o argumento de Locke em defesa do direito de resistência a partir da análise da referida obra e seu contraste com o Patriarcha (obra de Robert Filmer que Locke ataca em Dois Tratados); do contexto histórico e de alguns dos seus principais comentadores. Ainda que, segundo Locke, o Estado tenha surgido para proteger os direitos individuais como a liberdade e a propriedade, o governante está sujeito a se corromper e utilizar sua posição para praticar a injustiça contra seus súditos. O direito de resistência, apoiado na lei da natureza que permanece em vigor mesmo no estado civil, é o último recurso dos indivíduos contra a tirania praticada pelo governante corrompido.

Palavras-chave: Locke, Tirania, Resistência.

ABSTRACT: In his major political work, Two Treatises on Government, Locke defends the right of peoples to resist the sovereign. However, according to Locke, the human being voluntarily leaves state of nature to create the political state hoping that political power will soften the inconveniences of the state of nature. If the creation of the political state is voluntary, under what circumstances should the sovereign's determinations be resisted? Moreover, how do we base the right of resistance on the sovereign that was instituted with the permission of the individual himself who now intends to resist his determinations? The purpose of this paper is to discuss the reasons why the defence of the right of resistance becomes necessary in Locke's political thinking, and in what form and on what grounds Locke defends such a right in the Second Treatise on Government. It is intended to reconstruct Locke's argument in defence of the right of resistance from the analysis of that work in contrast with Patriarcha (Robert Filmer's work that Locke attacks in Two Treatises); the historical context and some of Locke's main commentators. Although, according to Locke, the state has arisen to protect individual rights such as liberty and property, the individual who responds by the actions of sovereign power can be corrupted and use his position to practice injustice against his subjects. The right of resistance, supported by the law of nature that remains in force even in civil society, is the last resort of individuals against the tyranny practiced by the corrupt ruler.

Keywords: Locke, Tyranny, Resistance. 


\section{Introdução}

Em Dois Tratados Sobre o Governo, sua principal obra política, Locke defende o direito dos súditos de resistir às ações do monarca. Entretanto, o próprio Locke, na mesma obra, descreve a origem do Estado político como fundada na livre determinação de indivíduos em estado de natureza que decidem estabelecer o poder soberano através do contrato social.

Se o poder político foi estabelecido pela vontade individual, em que circunstâncias será possível resistir às ordens do soberano? E, além disso, como se fundamenta esse direito de resistência contra o Estado? Ou seja, se o Estado é a autoridade legisladora reconhecida por todos, a princípio, só se poderia pensar em um direito de resistência se houvesse o próprio Estado feito aparecer uma lei que concedesse tal direito. Por isso mesmo o fundamento do direito de resistir precisa ser encontrado fora do Estado ${ }^{1}$.

Para Locke, o problema da interação humana tem como base principal a ausência do reconhecimento de uma norma comum que estabeleça um padrão de comportamento para evitar os conflitos entre os indivíduos. A norma que cumpre essa função existe desde antes do estabelecimento do Estado político e sua existência em nada depende dele. Trata-se da lei da natureza, uma lei da razão que deve ser encontrada por cada um através da reflexão e que, se bem compreendida, evita o estado de guerra que macula o estado de natureza.

Indivíduos que agem sem levar em conta os pressupostos da lei da natureza agem de maneira arbitrária, segundo seu próprio capricho interior, ignorando aquilo que é bom para todos segundo uma regra da razão que pode ser reconhecida por todos.

Analogamente, governantes que agem sem observar tanto a lei da natureza quanto as leis positivas agem também de forma arbitrária, segundo sua própria soberba e ignorando aquilo que é bom para toda a sociedade.

Locke caracteriza como tirânico o governo que ignora as leis e se orienta apenas pela prepotência do governante. O único remédio que o povo tem contra um governo tirânico é o direito de resistir às suas ações até que se possa substitui-lo. Nesse caso, a lei da natureza, que mesmo após o estabelecimento do Estado político continua em vigor, representa uma espécie de permissão moral para a desobediência sempre que o povo entender que a ação do governante não tem em vista a preservação da sociedade.

No presente artigo, pretende-se analisar os argumentos de Locke em favor do direito de resistência, a partir da recuperação do contexto histórico em que surgem os Dois Tratados (ou seja, em meio à disputa pelo poder político travada na Inglaterra do final do século XVII pelos defensores do absolutismo e seus opositores); e a partir da reconstrução da descrição que Locke faz do surgimento da sociedade política, partindo do estado de natureza, onde o poder arbitrário individual conduz ao estado de guerra; até a tirania, onde o governo arbitrário caracterizado pelo abuso do poder político conduz à quebra da relação de confiança entre povo e governante e faz voltar ao primeiro plano a lei da natureza para fundamentar o direito do povo de resistir ao tirano.

\footnotetext{
1 Muito embora o direito de resistência possa ser concedido pela própria ordem constitucional, como aconteceu, por exemplo, com a Revolução americana (a segunda emenda à constituição americana, de 1791, é associada ao direito de resistência à opressão), para a tradição jusnaturalista a qual Locke se vincula, é importante estabelecer o direito de resistência como anterior e independente do Estado. Assim, o direito de resistência está fundado na lei da natureza, na razão e na determinação de Deus (o apelo ao céu!). Ele é válido, para Locke, ainda que o Estado não o reconheça. Fritz (2008) discute o direito de resistência à tirania na tradição constitucional americana.
} 


\section{Os Dois Tratados Sobre o Governo e seu contexto}

Os Dois Tratados Sobre o Governo foram publicados em 1689, mas começaram a ser escritos alguns anos antes quando se desdobrava na Inglaterra a chamada crise de exclusão. Trata-se de uma disputa em relação à sucessão do trono inglês que poderia tornar rei um monarca de tendências absolutistas. O então monarca Carlos II não possuía herdeiros diretos. Seu irmão, Jaime, tornou-se o herdeiro presuntivo. Jaime, porém, era católico, fato que suscitava o temor de que ele pudesse se tornar um monarca absoluto à moda de Luís XIV, rei da França e exemplo maior de governante absolutista. Em função desse cenário surgiram dois partidos políticos: o partido Tory que, alinhado ao absolutismo, defendia o direito de Jaime a herdar a coroa do seu irmão; e o partido Whig que tentou aprovar uma lei no parlamento para excluir Jaime da linha de sucessão ao trono. Assim, Tories e Whigs encarnavam polos opostos de uma disputa que repercutia na questão dos fundamentos, das origens, da extensão e dos fins do governo civil.

Ligado aos Whigs, Locke teria participado ativamente de articulações cujo propósito era afastar do trono inglês monarcas de tendências absolutistas. Sua estreita amizade com o Lorde Ashley-Cooper, o Conde de Shaftesbury, custou-lhe inclusive alguns anos de exílio na Holanda, sob acusação de participação em um plano para assassinar o rei. Porém, a maior contribuição de Locke ao ataque ao absolutismo foi no campo teórico. Principalmente com a publicação dos Dois Tratados Sobre o Governo que cumprem o papel de combater o absolutismo e, ao mesmo tempo, oferecer uma resposta teórica para o problema do fundamento do poder político.

A defesa lockeana do direito de resistência, dessa maneira, se desdobrava no domínio prático. Ou seja, era conveniente que houvesse uma justificativa de ordem jurídico-moral para resistir a um eventual governo absoluto de Jaime II ou de qualquer outro na linha de sucessão ao trono que pretendesse exercer o governo de forma absolutista.

Locke começou a redigir os Dois Tratados por volta do início da década de $1680^{2}$. A obra, porém, só veio a público em 1689, logo após a chegada do "grande restaurador" (como Locke o saúda no prefácio da $\mathrm{obra}^{3}$ ), Guilherme de Orange, ao solo inglês. Esse evento, que afastou Jaime do trono inglês e com ele o risco de uma monarquia absoluta na Inglaterra, é o ponto alto da chamada "Revolução Gloriosa" que marca o momento em que o poder da coroa Inglesa passou a ser limitado pelo parlamento.

Nesse contexto de disputa teórico-política em torno da sucessão ao trono, os Tratados de Locke (o Primeiro Tratado especialmente) atacavam um texto que fora republicado em 1679 e era utilizado pelos Tories para fundamentar o governo absolutista. Trata-se da obra Patriarcha, escrita alguns anos antes por Robert Filmer ${ }^{4}$. Seu conteúdo agradava aos membros do partido Tory, "partidários da tradição e da coroa" que,

2 Sobre o período em que os Dois Tratados teriam sido escritos, Worden, (1998, p.306), afirma: “Peter Laslett [...] argumentou, com grande persuasão e precisão, que [a composição dos Dois Tratados] não data das consequências imediatas da Revolução de 1688-89, mas do início daquela década [e] a maior parte do Segundo Tratado foi escrita pela primeira vez durante o inverno de 1679-80, e o Primeiro Tratado, em 1680, com acréscimos aos primeiros feitos em 1681 e contínuas alterações e emendas em 1682 e 1683, seguidas de revisões finais em 1689. Ashcraft, em contraste, acredita que o Primeiro e Segundo Tratados foram escritos nessa ordem durante 1681-82; isto é, não enquanto a Exclusão [...] ainda estava em curso, ou pelo menos prestes a terminar, [mas] depois de Shaftesbury e seus aliados terem sido derrotados e terem virado da oposição política para planos de rebelião armada".

3 "Espero que estas [páginas], sejam suficientes para consolidar o trono de nosso grande restaurador, o atual rei Guilherme, para confirmar seu título no consentimento do povo" (LOCKE, 2005, p.197).

${ }^{4}$ Segundo Pocock (1975, p.432), o início da redação dos Dois Tratados Sobre o Governo, de Locke, foi consequência da republicação do Patriarcha, de Filmer, em 1679. 
segundo Laslett (1949, p.34s) ${ }^{5}$, "procuravam um argumento que negasse [...] que o fundamento do governo fosse o consentimento. E eles encontraram isso nos escritos de Filmer"; especialmente no Patriarcha, "possivelmente a afirmação política mais poderosa do absolutismo real no século XVII” (POCOCK, 1993, p106). Portanto, se por um lado os Tories tinham o Patriarcha para sustentar suas teses, por outro, os Whigs tinham Locke, "um defensor, até mesmo um arquiteto, da ideologia whig e [que] estava intimamente associado aos seus principais políticos” (KNIGHTS, 2005, p.346).

No âmbito da teoria absolutista de Filmer, a defesa do direito de o indivíduo resistir às ações do monarca era inviável, pois Filmer acreditava que a monarquia tinha origem na determinação de Deus. Assim, resistir às ordens do monarca equivalia a resistir às ordens de Deus e equivalia também à recusa em obedecer à ordem natural do mundo, uma vez que a ordem natural do mundo está relacionada com a determinação de Deus.

Além disso, para Filmer, o monarca não pode estar sujeito a qualquer lei, pois é ele mesmo o fundamento da autoridade da lei. Como só o monarca pode legislar, ele não poderá também estar sujeito à lei que ele mesmo editou.

Locke precisará também enfrentar essa abordagem filmeriana sobre o fundamento da lei e da autoridade para poder justificar o direito de resistência. Portanto, a defesa do direito de resistência, além de passar pelo contexto de instabilidade política que a Inglaterra vivia no final do século XVII, passa também pela refutação teórica da doutrina absolutista de Robert Filmer.

\section{Origem e desenvolvimento da sociedade política nos Dois Tratados}

$\mathrm{Na}$ forma como Locke explica a origem da sociedade política, pode-se identificar um desenvolvimento linear que parte do estado de natureza e cujo ponto alto é o governo constitucional. Quando a sociedade atinge a forma de um governo constitucional estaria dada a receita para uma vida politicamente perfeita. O problema é que há uma premissa que perpassa toda a obra de Locke e que constitui um permanente incômodo à vida social: a de que os seres humanos podem sempre degenerar.

No estado de natureza como Locke propôs, não há, definitivamente, uma guerra de todos contra todos (como na teoria de Hobbes). O ser humano não é essencialmente mau. Mas é degenerável, e essa possibilidade de degeneração o obriga a procurar meios para evitar a ruina que dela advém. O ciclo que a sociedade percorre é este: no estado de natureza tudo vai bem até que a degeneração de alguns obriga a criação, através de um contrato, da sociedade política e confere a um só indivíduo o poder de julgar imparcialmente todas as controvérsias. Esse indivíduo, que se tornou o soberano, degenera e passa a abusar do poder que lhe foi confiado. Os homens então, para frear o impulso arbitrário do soberano, estabelecem o poder legislativo. Daí em diante, as leis deverão ser o limite para a ação do monarca.

Para cada etapa da degeneração, Locke apresenta um remédio adequado, de forma que os direitos fundamentais - dados pela lei da natureza - jamais se percam. Para o abuso cometido pelo indivíduo no estado de natureza, o estado civil é o remédio. Para o abuso cometido pelo monarca que governa de forma absoluta e sem leis, o poder legislativo independente é o remédio. E para o soberano que ignora as leis e passa a agir de forma tirânica e segundo seu próprio arbítrio, o remédio será um eterno direito de resistência fundado na lei da natureza que nunca perde sua eficácia, mesmo diante das leis positivas do estado civil.

${ }^{5}$ Quando se tratar de referência a textos que não estejam em português, a tradução será sempre nossa. 
No estado de natureza, onde o único direito que existe é aquele derivado da lei da natureza, o poder arbitrário que um indivíduo pode ter sobre outro se manifesta na violação dessa lei, que culmina com o estado de guerra: "aquele que tenta colocar a outrem sob seu poder absoluto põe-se consequentemente em estado de guerra com ele” (LOCKE, 2005, p.396, \$17) e, segundo Locke, “evitar esse estado de guerra [...] é a grande razão pela qual os homens se unem em sociedade e abandonam o estado de natureza" (LOCKE, 2005, p.400, §21).

É importante não perder de vista o papel que a lei da natureza exerce na estrutura da argumentação de Locke. Assim, a abordagem de Locke da lei da natureza aponta para o fato de os indivíduos possuírem direitos independentemente do Estado político. Trata-se de um direito supremo capaz de dar garantias aos indivíduos contra arbitrariedades do soberano. Afirma Harris (1994, p.208) que "o tratamento dado por Locke à lei da natureza foi calculado não somente para mostrar como o povo pode produzir um tipo próprio de governo civil, mas também que um governo absoluto não era legítimo para eles".

O conceito de lei da natureza desenvolvido por Locke remete à regra fundamental que orienta a ação humana, sobretudo no estado de natureza. Menos do que uma lei em sentido estrito, trata-se de um ditame moral que pode ser reconhecido pela razão, pois para Locke "a lei da natureza era, em sua essência, mais uma lei moral que uma lei política" (GOUGH, 1994, p.25). Não por acaso, se afirma que é justamente a "deterioração moral que leva os homens a abandonarem o estado de natureza" (SELIGER, 1963, p.350). A lei da natureza deve indicar, no estado de natureza e fora dele, o melhor modo da ação humana com vista a auto conservação e à conservação de toda a humanidade:

o estado de natureza tem para governá-lo uma lei da natureza, que a todos obriga; e a razão, em que essa lei consiste, ensina a todos que [...] cada um está obrigado a preservar-se, e [...] tanto quanto puder, preservar o resto da humanidade (LOCKE, 2005, p384s, \$6)

Entretanto, como os seres humanos degeneram, essa degeneração é o motivo para abandonar o estado de natureza e estabelecer, pelo contrato, a sociedade civil:

não fosse a corrupção e a perversidade de homens degenerados, não haveria necessidade de nenhum outro poder - não seria preciso que os homens se afastassem desta grande comunidade natural e se unissem, mediante acordos positivos, em sociedades menores e separadas (LOCKE, 2005, p. 498, \$128).

Quando o Estado político, mediante um acordo entre os indivíduos, é finalmente estabelecido, a responsabilidade pelo exercício do poder político, principalmente naquilo que se refere ao poder de julgar as controvérsias, é confiada a uma pessoa. O patriarca da família assume inicialmente essa função porque "a preeminência do pai [colocou] no começo, o poder em uma só mão” (LOCKE, 2005, p.478, \$106).

Entretanto, estabelecer um estado político no qual é confiado a um indivíduo o poder exclusivo de julgar as controvérsias e executar as punições não é o bastante para garantir a paz e a justiça ao corpo da sociedade. É preciso ainda que haja "uma lei estabelecida, fixa e recebida e aceita mediante o consentimento comum enquanto padrão da probidade e da improbidade, e medida comum para solucionar todas as controvérsias entre [os homens]" (LOCKE, 2005, p.496, \$124).

Aquele a quem inicialmente se confiou o governo da sociedade, o monarca, se degenera na medida em que a "ambição e o fausto" aumentam seu poder, ensinando-o a "ter interesses distintos e separados dos de seus povos” (LOCKE, 2005, p.485, \$111). E assim as leis positivas surgem para limitar e orientar as ações 
do governante. Ou seja, combate-se o poder arbitrário do estado de natureza com o contrato que designa apenas um indivíduo para julgar as controvérsias. Em seguida, quando esse indivíduo se deixa tomar pela ambição de possuir mais poder e seus súditos percebem que "muito pior é a condição de quem está exposto ao poder de um só homem a comandar cem mil homens outros do que a de quem está exposto ao poder arbitrário de cem mil homens isolados” (LOCKE, 2005, p.508, §137), são criadas as leis para guiar e justificar suas ações.

A existência de leis, entretanto, não impede que o governante se corrompa, e passe a exercer o poder “além do direito" (LOCKE, 2005, p.561 \$199). O governo tirânico, definido por Locke no penúltimo capítulo do Segundo Tratado, é a última possibilidade de manifestação do poder arbitrário, depois das leis serem estabelecidas. Precisamente, nas palavras do autor, a tirania ocorre quando o governante "não faz da lei, mas de sua vontade, a regra, e suas ordens e ações não estão dirigidas à preservação das propriedades de seu povo, mas à satisfação de sua própria ambição" (LOCKE, 2005, p.561, \$199).

Nesta situação extrema, em que o governante rompe com a confiança nele depositada, o povo tem o direito de resistir às ações ilegítimas. A lei da natureza, que nunca perdeu a validade apesar de todo o desenvolvimento da sociedade e das leis positivas, volta à tona para fundamentar o direito a resistência contra a tirania.

\section{Tirania e direito de resistência}

Aqueles indivíduos que por degenerarem tornam o estado de natureza inviável continuam sujeitos à degeneração após o estabelecimento do estado civil. Diante de um governante que passe a exercer o poder sem respeito às leis estabelecidas e, por conseguinte, diante do risco de desrespeito aos direitos individuais garantidos pela lei da natureza, o indivíduo mesmo em sociedade, dispõe de poder suficiente para se rebelar. Assim, "os dois estados, natural e civil, estão intimamente interligados: um é o remédio do outro" (BOBBIO, 1997, p.239).

Nesses termos pode-se estabelecer uma diferença, ainda que muito sutil, entre o absolutismo, principal alvo de Locke nos Dois Tratados, e a tirania: enquanto o primeiro diz respeito ao soberano que governa sem leis - pois não pode haver nenhuma lei que limite seu poder; a tirania diz respeito a um soberano criado por contrato ou por encargo fiduciário (como Locke prefere), mas que deixa de cumprir sua parte do acordo ao ignorar as leis e agir segundo seu próprio arbítrio. Enquanto o monarca absolutista é alguém cujo poder não pode ser limitado porque dele depende o direito e nele está a origem e fundamento das leis positivas, o tirano é aquele que sabe que o fundamento do seu poder, o fundamento da soberania e das leis positivas, está, em última instância, no consentimento do povo, mas ainda assim sobrepõe sua própria vontade à do povo, e seu próprio arbítrio sobre as regras legitimamente promulgadas pelo povo ou em nome do povo.

Locke oferece, no Segundo Tratado, alguns exemplos das formas pelas quais a sociedade civil degenera ${ }^{6}$. O foco neste trabalho será a última delas: a tirania, que constitui uma forma de ruína da sociedade civil na medida em que o governante, que fora legitimamente constituído, deixa de agir segundo o interesse do povo e dentro dos limites da lei, e passa a agir segundo seu próprio arbítrio: "onde termina a lei começa a tirania" (LOCKE, 2005, 563, \$202).

6 "Locke examina em quatro capítulos diferentes, quatro formas de degeneração da sociedade civil: a conquista, a usurpação, a tirania e a dissolução do governo" (BOBBIO, 1997, p.240). 
Nas palavras de Locke (2005, p.560-561, \$199), a tirania consiste em “exercer o poder além do direito”. Essa forma de poder arbitrário surge

quando o governante, seja lá que título tenha, não faz da lei, mas de sua vontade, a regra, e suas ações não estão dirigidas à preservação das propriedades de seu povo, mas à satisfação de sua própria ambição, vingança, cobiça ou qualquer outra paixão irregular (LOCKE, 2005, p.560s, \$199).

Contra o governante que age de forma tirânica, em franca desconsideração das limitações legais, a doutrina política de Locke assegura o direito de resistir, pois "nada poderia levantar mais a hostilidade de Locke do que a justificativa de um poder político que está além de todos os direitos e além de qualquer moralidade" (POLIN, 1960, p.198). Dessa forma:

Todo aquele, que, investido de autoridade, exceda o poder que lhe é conferido por lei e faça uso da força que tem sob seu comando para impor ao súdito o que a lei não permite, deixa, com isso, de ser magistrado e, agindo sem autoridade, pode ser combatido, como qualquer outro homem que invade o direito alheio (LOCKE, 2005, p. 563, \$202).

Agir com autoridade, para Locke, é agir segundo as limitações conferidas pela lei. O soberano, ao abusar da autoridade, perde-a, vindo à tona o direito do povo, e mesmo do indivíduo ${ }^{7}$ de resistir à ação arbitrária $^{8}$. Apesar dos indivíduos contarem com a eterna garantia da lei da natureza em relação a alguns direitos fundamentais, no ato de criação da sociedade houve cessão de direitos e poderes individuais ao corpo político9. Por isso, o direito de resistência só se estabelece diante do abuso do poder, ou seja, o agir segundo a vontade própria em vez de agir segundo a lei: “a força não se deve opor a coisa alguma, além da força injusta e ilegítima” (LOCKE, 2005, p. 565, \$204).

Locke adverte que não apenas na monarquia, mas em todas as demais formas de governo está presente o risco da degeneração do governante no sentido da tirania:

sempre que o poder que é depositado em quaisquer mãos para o governo das pessoas e a preservação de suas propriedades se vê aplicado para outros fins, e usado para empobrecê-las, persegui-las ou submetê-las às ordens arbitrárias e irregulares dos que o detém, tal poder logo se torna tirania, pouco importando que aqueles que o usam, sejam um ou muitos (LOCKE, 2005, p.563, \$201)

Portanto, seu argumento não se constitui somente para combater o absolutismo monárquico, mas para combater o poder arbitrário em geral. Afinal, o arbítrio do julgamento em causa própria do estado de natureza produziu o incômodo ${ }^{10}$ que levou os homens à sociedade civil; o arbítrio do governo sem leis

${ }^{7}$ Locke não só legitima a resistência baseando-se inteiramente na linguagem dos direitos e dos direitos naturais, como também localiza a autoridade para resistir no "corpo do povo", e mesmo "num único homem", se este for "privado de seu direito (SKINNER, 1996, p.608).

8 Cabe aqui mencionar aquilo que Laslett $(2005$, p.168) chama de "perpétuo poder residual para afastar os governantes e remodelar o governo".

9 "Portanto, sempre que qualquer número de homens estiver unido numa sociedade de modo que cada um renuncie ao poder executivo da lei da natureza e o coloque nas mãos do público, então, e somente então, haverá uma sociedade política ou civil" (LOCKE, 2005, p.460, §89).

10 Do ponto de vista do pensamento moral de Locke, o incômodo tem um importante papel no sentido de motivar a ação. No Ensaio Sobre o Entendimento Humano, Locke é categórico: “o incômodo é a mola da ação" (LOCKE, 2012, 
produziu o incômodo que desaparece com o surgimento do governo limitado por leis; e, finalmente, o arbítrio do tirano que "coloca sua própria vontade arbitrária no lugar das leis, que são a vontade da sociedade” (LOCKE, 2005, p.574, \$214) produz o incômodo que, em última instância, justifica, à luz da lei da natureza, o direito de não obedecer:

sempre que tais legisladores tentarem violar ou destruir a propriedade do povo, ou reduzi-lo à escravidão sob um poder arbitrário, colocar-se-ão em estado de guerra contra o povo, que fica, a partir de então, desobrigado de toda obediência e deixado ao refúgio comum concedido por Deus a todos os homens contra a força e a violência (LOCKE, 2005, p.579s, \$222)

Como a lei da natureza não perde sua eficácia e como os direitos por ela gerados não desaparecem no estado civil, cada indivíduo pode resistir às ações arbitrárias de um governo tirano. Uma vez que é uma lei da razão, a lei da natureza, com seu caráter moralizador, permite que as circunstâncias sociais sejam alteradas sempre que a conservação dos indivíduos, sua liberdade e sua propriedade se encontrarem ameaçadas. Esse é o fundamento do último recurso que os indivíduos têm contra a ameaça da arbitrariedade e da tirania. Em último caso, quando o respeito às leis já não for o suficiente para frear a ambição e a degeneração arbitrária do espírito dos homens, o direito de resistir e de não obedecer às ordens injustas está garantido pela lei da natureza.

É ainda importante realçar o contraste do direito de resistência frente à principal obra que compunha o conjunto interlocutório dos Dois Tratados, trata-se do já mencionado Patriarcha de Robert Filmer, notável defensor do absolutismo monárquico e que não reconhecia a resistência como um direito natural do indivíduo.

Aquela característica que para Locke representa um desvio do poder soberano, qual seja, o exercício do poder sem a imprescindível submissão às leis, para Filmer era a condição necessária para que as leis pudessem existir e ter eficácia na sociedade, pois ele acreditava que só poderia haver lei se houvesse também um soberano com autoridade para outorgá-la. Para que uma lei tivesse força imperativa, ela precisaria derivar de uma autoridade que estivesse acima da própria lei, assim:

Não pode haver leis sem um poder supremo para impô-las ou ordená-las. Em todas as aristocracias, os nobres estão acima das leis e em todas as democracias, o povo. Pela mesma razão em uma monarquia, o rei deve necessariamente estar acima das leis. Não pode haver majestade soberana naquele que está debaixo deles (FILMER, 1949, p.105)

Portanto, o monarca filmeriano não degeneraria quando não agisse em estrito cumprimento às leis. De outro modo, toda e qualquer lei dependeria dele para ter eficácia; e ele, como possui uma autoridade superior às leis, a elas não estava submetido, por isso, certamente, a não obediência do governante às leis não configuraria degeneração do governo, segundo Filmer.

No argumento de Locke, é graças ao fato do processo de origem e desenvolvimento da sociedade humana ter se baseado na liberdade original do indivíduo, em vez da determinação de Deus ${ }^{11}$, que os seres

p.260, §34).

11 "Para Locke [...] a autoridade política deriva ou de Deus, ou do povo. Tendo rejeitado, no Primeiro Tratado, a defesa particular de Robert Filmer a favor da primeira concepção, Locke assume como axiomático que a autoridade política deriva do povo" (ASHCRAFT, 2011, p.281). 
humanos puderam procurar maneiras de restringir a atuação do governante.

Assim como a monarquia original e paterna se corrompe levando o povo a estabelecer leis para limitá-la, também aquele governante que, embora escolhido pelo povo, se corrompe e passa a agir sem a devida observação da lei e do bem comum, autoriza o povo a invocar o direito de resistir àquelas ações ilegítimas ${ }^{12}$. O fundamento desse direito de resistência é, em última instância, a lei da natureza ${ }^{13}$.

\section{Conclusão}

O direito de resistir às ações arbitrárias do governante é um elemento que torna singular o pensamento de Locke no contexto das disputas político-teóricas em torno da origem e dos fundamentos do governo. O direito de resistência, de fato, é o ponto alto do argumento de Locke, é o momento no qual Locke declara que a figura principal do jogo político é o indivíduo com seus direitos fundamentais.

O poder arbitrário é também expressão da individualidade que permeia o pensamento de Locke. Agir de forma arbitrária não é outra coisa senão agir estritamente de acordo com o juízo e sentimento internos. Para que a ação não seja arbitrária, ela deve estar baseada em um princípio que possa ser reconhecido por qualquer pessoa.

No estado de natureza, as ações que têm por fundamento a lei da natureza jamais são arbitrárias. Isso porque o conteúdo da lei da natureza pode ser conhecido por todos os indivíduos que dispõem do uso perfeito da razão. Como a recomendação da lei da natureza diz respeito apenas à conservação de cada um, agir dentro dos seus limites não gera injustiça.

Mas as ações que não têm por fundamento a lei da natureza são injustas e geram o estado de guerra. O desrespeito à vida, à propriedade e aos bens alheios, bem como a aplicação de uma punição desproporcional ao dano causado, são atitudes que não observam a justeza sugerida pela lei natural e, por isso, são arbitrárias.

Assim como também é arbitrário o poder do monarca que age sem levar em conta os pressupostos da lei da natureza e também das leis positivas. Apesar de controlar o instrumento estatal, não é legítimo ao monarca ultrapassar os limites demarcados pelas leis, sejam naturais ou positivas.

Contra esse monarca que abusa do poder político e age de forma arbitrária, só resta aos indivíduos o direito de resistir aos seus comandos invocando a autoridade conferida pela lei da natureza. O direito de resistência, finalmente, é um remédio jurídico contra os abusos do poder estatal.

A teoria política de Locke nos Dois Tratados Sobre o Governo, como já mencionado, não se limitou ao ataque à monarquia absoluta. Sua proposta foi além de simplesmente atacar o absolutismo dos Stuarts ${ }^{14}$. Mais que isso, Locke fundamentou o poder de reagir ao governo arbitrário, possua ele a forma que for, seja o monarca ou os membros do legislativo, ou até mesmo "aquele que tenta colocar outro homem sob seu

12 Segundo Marshall (1994, p.241s) no início da década de 1680, em meio à crise de exclusão e enquanto Locke já trabalhava nos Dois Tratados, ele viu a necessidade de procurar uma justificativa ao direito de resistência diante do receio das tendências absolutistas do rei Carlos II: "Locke pode ter começado a escrever a defesa da resistência do Segundo Tratado no início de 1682 [...] com a intenção de que pudesse ser publicada quando tal resistência fosse articulada".

13 "Pela lei fundamental da natureza, é impossível que o povo não tenha o direito de resistir a sua própria destruição. Portanto, ele deve ter o direito de resistir a um governo e recuperar o poder a que está sujeito. Essa é a razão mais plausível para Locke insistir que a comunidade deve ter o direito de resistência pela força" (THOMAZ, 2006, p.79).

14 Os Stuarts eram a dinastia que ocupava o trono inglês à época de Locke. 
poder absoluto" (LOCKE, 2005, \$17).

A justificação teórica do direito de resistir, além disso, possuía implicações práticas, pois promovia a aceitação moral da desobediência ao governo ${ }^{15}$. De certa forma, Locke sinalizou aos whigs de seu tempo que ainda que houvesse uma reviravolta absolutista na condução do Estado após a revolução de 1688-1689, os indivíduos poderiam invocar seus direitos naturais supra estatais para restabelecer a estrutura constitucional ${ }^{16}$ do Estado.

\section{Referências}

AARON, R.I. John Locke. Oxford: Oxford, Clarendon, 1965.

ASHCRAFT, R. A Filosofia Política. In: CHAPPELL, V. (org.). LOCKE. Tradução: Guilherme Rodrigues Neto. Aparecida: Ideias e Letras, 2011.

BOBBIO, N. Locke e o Direito Natural. Tradução: Sérgio Bath. Brasília: UnB, 1997.

FILMER, R. (1679). Patriarcha and other political Works. Edited by Peter Laslett. Oxford: Blackwell, 1949.

FRITZ, C.G. American Sovereigns the people and America's constitutional tradition before the civil war. Cambridge: Cambridge University Press, 2008.

GOUGH, J.W. Introdução. In: LOCKE, J. Segundo Tratado Sobre o governo civil. Tradução: Magda Lopes e Marisa Lobo da Costa. Rio de Janeiro: Vozes, 1994.

HARRIS, I. The mind of John Locke. Cambridge: Cambridge University Press, 1994.

KNIGHTS, M. Representation and Misrepresentation in Later Stuart Britain. Oxford: Oxford University Press, 2005.

LASLETT, P. A teoria social e política dos Dois tratados sobre o governo. In: LOCKE. J. Dois tratados sobre o governo. Tradução: Julio Fischer. 2. ed. São Paulo: Martins Fontes, 2005.

. Introdução ao Patriarcha. In: FILMER, R. Patriarcha and other political Works of sir Robert Filmer. Edited by Peter Laslett. Oxford: Blackwell, 1949.

LOCKE, J. (1689). Dois Tratados Sobre o Governo. Tradução: Julio Fischer. $2^{\circ}$ ed. São Paulo: Martins Fontes, 2005.

. (1690). Ensaio sobre o entendimento humano. Trad. Pedro Paulo Pimenta. São Paulo: Martins Fontes, 2012.

MARSHALL, J. John Locke: resistance, religion and responsibility. Cambridge: Cambridge University Press, 1994.

POCOCK, J. G. A. (ed.) The varieties of British political thought, 1500-1800. Cambridge: Cambridge University Press, 1993.

15 "O problema de Locke é encontrar uma constituição para uma comunidade que esteja determinada a permanecer livre, determinada a evitar a tirania de qualquer forma. E ele propõe este sistema de controle e verificação em que aqueles que possuem autoridade são limitados em seus poderes e são por toda parte responsáveis por suas ações" (AARON, 1965, p.282).

16 "As teorias baseadas em direitos têm dois gumes em potencial: de um lado, validam regimes constitucionais que são projetados para proteger os direitos legítimos de seus membros, e, de outro, justificam a resistência quando o governo excede sua autoridade e ameaça em vez de proteger as pessoas" (POCOCK, 1993, p.327). 
. The Machiavellian Moment: Florentine Political Thought and the Atlantic Republican Tradition. Princeton, 1975.

POLIN, R. La politique morale de John Locke Paris: PUF, 1960.

SELIGER, M. Locke, liberalism and nationalism. In: YOLTON, J.W. (ed.) John Locke: problems and perspectives. Cambridge: Cambridge University Press, 1969.

SKINNER, Q. As fundações do pensamento político moderno. Trad. R. J. Ribeiro e L. T. Motta. São Paulo: Companhia das Letras, 1996.

THOMAZ, D. A. L. Locke on government. London: Routledge, 2006.

WORDEN, B. Soldiers, Writers and Statesmen of the English Revolution. Cambridge: Cambridge University Press, 1998.

Artigo recebido em: 31 de maio de 2019

Artigo aceito em: 02 de julho de 2019 